\title{
A Transaminase Triggered Aza-Michael Approach for the Enantiose- lective Synthesis of Piperidine Scaffolds
}

\author{
James Ryan, ${ }^{\dagger}$ Mindagus Siauciulis, ${ }^{\ddagger}$ Andrew Gomm, ${ }^{\ddagger}$ Beatriz Maciá, ${ }^{*} \dagger$ Elaine O’Reilly, ${ }^{*}$, Vittorio

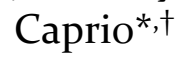

${ }^{\dagger}$ Faculty of Science \& Engineering, Division of Chemistry \& Environmental Science, Manchester Metropolitan University, Chester Street, Manchester M1 5GD, United Kingdom

${ }^{\ddagger}$ School of Chemistry, University of Nottingham, University Park, Nottingham NG7 2RD, United Kingdom

Supporting Information Placeholder

\begin{abstract}
The expanding "toolbox" of biocatalysts opens new opportunities to redesign synthetic strategies to target molecules by incorporating a key enzymatic step into the synthesis. Herein, we describe a general biocatalytic approach for the enantioselective preparation of 2,6-disubstituted piperidines starting from easily accessible pro-chiral ketoenones. The strategy represents a new biocatalytic disconnection, which relies on an $\omega$-TA-mediated aza-Michael reaction. Significantly, we show that the reversible enzymatic process can power the shuttling of amine functionality across a molecular framework, providing access to the desired aza-Michael products.
\end{abstract}

The intramolecular aza-Michael reaction (IMAMR) is a powerful method for the preparation of simple and architecturally complex nitrogen heterocycles and alkaloid skeleta. ${ }^{1}$

An ideal strategy for the synthesis of such heterocycles and alkaloids is a tandem reductive amination/IMAMR sequence (Figure 1), allowing direct, one-pot conversion of readily available prochiral ketoenones $\mathbf{2}$ to stereodefined, highly functionalized cyclic products $\mathbf{1}$. However, the approach is dependent upon amination conditions where there is i) no reduction of the double bond, ii) no amination of the enone carbonyl, iii) stereoselective amination of the desired ketone and iv) no amination of the pendent piperidine ketone. Owing to these demands, the strategy outlined in Figure 1 is currently beyond traditional chemical synthesis and IMAM strategies are characterised by step-wise introduction of N/O-functionality with a consequent reliance on protecting group manipulations. ${ }^{2}$

Biocatalysis allows us to reevaluate synthetic strategies and enables disconnections that are not possible using traditional chemical synthesis or catalysis. $3 \omega$-Transaminase ( $\omega$-TA) enzymes are emerging as extremely important catalysts for the synthesis of optically pure chiral amines starting from readily available prochiral ketones. 4 Despite the challenges associated with the use of $\omega$-TAs, including the necessity for high equivalents of sacrificial amine donor, the application of an $(R)$-selective $\omega$-TA variant for the industrial-scale synthesis of the anti-diabetic drug, Sitagliptin, highlights their enormous synthetic potential. ${ }^{a}$ These enzymes rely on the cofactor pyridoxyl-5'-phosphate (PLP) to mediate the amination of ketones, 5 with no requirement for reducing agents, and therefore have the potential to be applied effectively for the synthesis of a broad range of piperidines following the strategy outlined in Figure 1. While previous studies have shown that excellent regioselectivity can be achieved in the conversion of sterically demanding 1,4- and 1,5-diketones bearing one bulky group, ${ }^{6}$ there is no literature precedence for such selectivity on substrates with two accessible ketones.

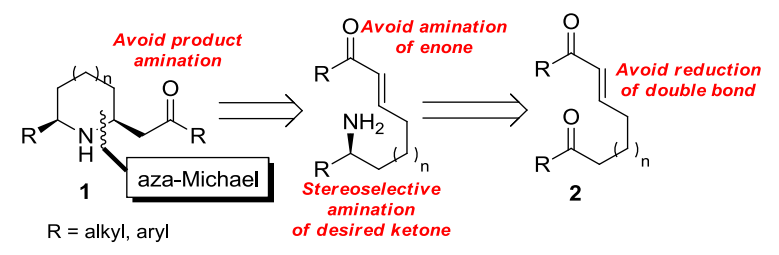

Figure 1. An attractive retrosynthesis for the preparation of heterocycles and alkaloids starting from ketoenones.

Here we describe a new biocatalytic disconnection for the regio- and stereoselective synthesis of a range of 2,6-disubstituted piperidines exploiting a key biocatalytic transamination followed by a spontaneous IMAMR. Furthermore, for substrates where high regioselectivity is not expected, we specifically exploit the reversible nature of the biocatalytic amination process to ensure that the amine functionality is ultimately installed at the desired position in a strategy that would not be possible using a classical reductive amination.

Two commercially available $\omega$-TA biocatalysts from Codexis, which have complementary selectivity, were chosen to evaluate the methodology on a small panel of diketones za-e. These diketones are readily available via oxidative cleavage of 1methylcyclopentene followed by reaction with a suitable 
phosphorus ylid (see ESI). Complete regioselectivity in the amination step of ketones $3 \mathbf{a}-\mathbf{d}$ was anticipated from previous literature. ${ }^{6}$ As expected, both the $(S)$ - and $(R)$-selective $\omega$-TA enzymes mediated the transamination reaction exclusively on the methyl ketone in $>99 \%$ ee (Table 1 ). Following transamination, a spontaneous IMAMR occurs, providing the 2,6-disubstituted piperidines 7 as a mixture of diastereoisomers. Conveniently, epimerization readily occurred upon standing in $\mathrm{MeOH}$, presumably via a retro-aza-Michael reaction, ${ }^{8}$ providing products $\mathbf{4}$ - $-\mathbf{d}$ in $>99 \%$ de. A particularly important aspect of this transformation is the requirement for only 2 equivalents of the low-cost isopropylamine donor in the absence of in-situ by-product removal strategies, owing to the powerful driving force of the 1,4-addition reaction. Firstly, this gave us confidence that the reversible amination strategy could be successfully exploited for the conversion of substrates with two accessible ketones. Additionally, employing these conditions does not lead to any undesired amination of the product pendent ketone. The aza-Michael reaction also drives amination of bulkier ketones and a reversal in the selectivity previously observed during transamination of $1,4 / 1,5^{-}$ dicarbonyls. ${ }^{6}$ Thus, ethylketoenone ze provides piperidine $\mathbf{4 e}$, albeit with reduced yield/ee, using the alternate $(S)$-selective ATA256. ${ }^{8}$

Table 1. $\omega$-TA-mediated transamination/IMAMR cascade of ketoenones $3 a-e .^{a}$

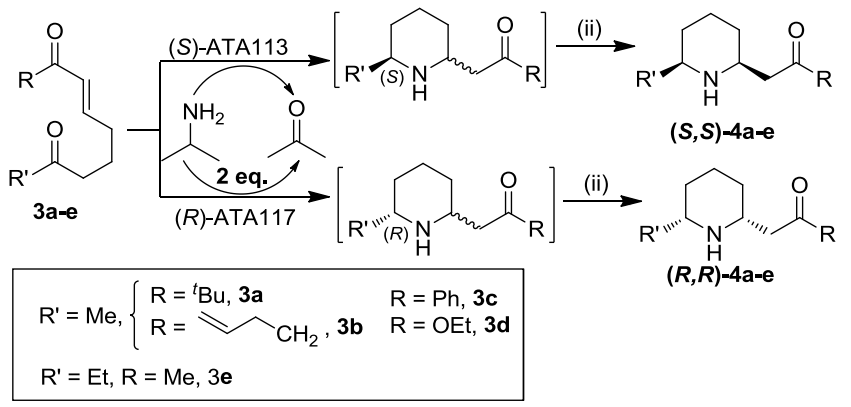

\begin{tabular}{|c|c|c|c|c|c|}
\hline Substrate & $\omega-\mathrm{TA}$ & $\begin{array}{l}\text { Conv } \\
(\%)^{\mathrm{b}}\end{array}$ & $\begin{array}{l}\text { ee } \\
(\%)^{c}\end{array}$ & $\begin{array}{l}\text { de } \\
(\%)^{d}\end{array}$ & $\begin{array}{l}\begin{array}{l}\text { Yield } \\
(\%)^{\mathrm{e}}\end{array} \\
\end{array}$ \\
\hline $3 a$ & ATA113 & $>99^{f}$ & $>99$ & $>99^{g}$ & $78(S, S)^{\mathrm{h}}$ \\
\hline $3 a$ & ATA117 & $>99^{f}$ & $>99$ & $>99^{\mathrm{g}}$ & $88(R, R)^{\mathrm{h}}$ \\
\hline $3 b$ & ATA113 & $>99$ & $>99$ & $>99$ & $92(S, S)^{\mathrm{h}}$ \\
\hline $3^{b^{i}}$ & ATA117 & $>99^{f}$ & $>99$ & $>99$ & $90(R, R)^{\mathrm{h}}$ \\
\hline 3c & ATA113 & $>99$ & $>99$ & $>99$ & $76(S, S)^{\mathrm{h}}$ \\
\hline $3 c^{i}$ & ATA117 & $50^{f}$ & $>99$ & $>99$ & $44(R, R)^{\mathrm{h}}$ \\
\hline 3d & ATA113 & $>99$ & $>99$ & $>99^{j}$ & $72(S . S)^{\mathrm{h}}$ \\
\hline 3d & ATA117 & $>99$ & $>99$ & $>99^{j}$ & $70(R, R)^{\mathrm{h}}$ \\
\hline $3 \mathrm{e}^{\mathrm{i}, \mathrm{k}}$ & ATA256 & $>99^{\mathrm{f}}$ & $70^{1}$ & $>99$ & $50(S, S)^{\mathrm{h}}$ \\
\hline
\end{tabular}

a Reaction conditions: (i) $\omega$-TA $(5 \mathrm{mg} / \mathrm{mL})$, substrate $(50 \mathrm{mM})$, isopropylamine (100 mM), pyridoxyl-5'-phosphate (PLP, $2 \mathrm{mM})$, HEPES buffer (100 mM, pH 7.5), $30^{\circ} \mathrm{C}, 150$ RPM, 24 h; (ii) $\mathrm{MeOH}$, r.t., 24 h. ${ }^{b}$ Conversion determined by ${ }^{1} \mathrm{H}-\mathrm{NMR}$ after $24 \mathrm{~h}$. ${ }^{c}$ ee determined by chiral GC or HPLC (see ESI). ${ }^{d}$ de determined by NMR after the epimerization step. ${ }^{e}$ Isolated yield after flash chromatography. ${ }^{\mathrm{f}}$ Conversion after $48 \mathrm{~h}$. ${ }^{\mathrm{g}}$ Epimerization was carried out at $65^{\circ} \mathrm{C}$ for $24 \mathrm{~h}$. ${ }^{\mathrm{h}}$ Configuration assigned by analogy with $\mathbf{3} f$ and in agreement with NOESY experiments (see ESI). ${ }^{\mathrm{i}} 4$ equivalents of isopropylamine were used. ${ }^{j}$ Epimerization was carried out in EtOH at $80{ }^{\circ} \mathrm{C}$ for $24 \mathrm{~h}$. ${ }^{\mathrm{k}}$ Reaction carried out at $50^{\circ} \mathrm{C} .{ }^{1}$ See reference 8 .
In light of this, it was envisaged that the same methodology could be employed to access the naturally occurring defense alkaloid (-)-pinidinone $\mathbf{4}^{\mathbf{f}, 10}$ from the corresponding dimethyl ketoenone $\mathbf{3 f}$ (Scheme $\mathbf{1}$ ). An additional level of complexity is associated with this diketone as the $\omega$-TA is not expected to show any regioselectivity in the amination step. We reasoned that while two amine products would initially be formed resulting from amination of the methyl ketone and enone, the reversible nature of the biocatalytic amination coupled with the spontaneous 1,4-addition would drive the shuttling of the undesired amine to allow exclusive isolation of (-)-pinidinone $4 \mathbf{f}$ and trans-5f. As expected, incubation of $\mathbf{3} \mathbf{f}$ with ATA117 afforded a mixture of diastereoisomers $\mathbf{4} \mathbf{f}$ and $\mathbf{5} \mathbf{f}$ with $>99 \%$ conversion and $>99 \%$ ee, which was easily epimerized to (-)pinidinone 4 f with $>99 \%$ de (Table 2 ). Comparable results were obtained with $(S)$-selective ATA113. We have also demonstrated that 1.1 equivalents of the amine donor were sufficient to achieve $>99 \%$ conversion (Table 2 , footnote $\mathrm{f}$ ). The synthetic utility of our methodology is showcased by the ease of upscaling, allowing access to $0.48 \mathrm{~g}$ of (-)-pinidinone employing only 2 eq of isopropylamine (Scheme 1 ).

Table 2. Results from biotransformations with $3 \mathrm{f} \mathrm{em-}$ ploying ATA113 and ATA117. ${ }^{a}$

\begin{tabular}{llllll}
\hline Substrate & $\omega-T A$ & $\begin{array}{l}\text { Conv } \\
(\%)^{b}\end{array}$ & $\begin{array}{l}\text { ee } \\
(\%)^{c}\end{array}$ & $\begin{array}{l}\text { de } \\
(\%)^{d}\end{array}$ & $\begin{array}{l}\text { Yield } \\
(\%)^{\mathrm{e}}\end{array}$ \\
\hline 3f & ATA113 & $>99^{\mathrm{f}}$ & $>99$ & $>99$ & $91(S, S)^{\mathrm{g}}$ \\
3f & ATA117 & $>99^{\mathrm{f}}$ & $>99$ & $>99$ & $90(R, R)^{\mathrm{g}}$ \\
\hline
\end{tabular}

a-e See Table 1 footnotes. ${ }^{\mathrm{f}}$ This transformation could also be carried out using 1.1 eq. of isopropylamine $(55 \mathrm{mM})$ with identical conversion. ${ }^{g}$ Absolute configuration determined by correlation with known compounds (see ESI).

Scheme 1. Preparative scale conversion of $3 \mathrm{f}$ to $4 \mathrm{f}(-)$ pinidinone using $(R)$-selective ATA117.

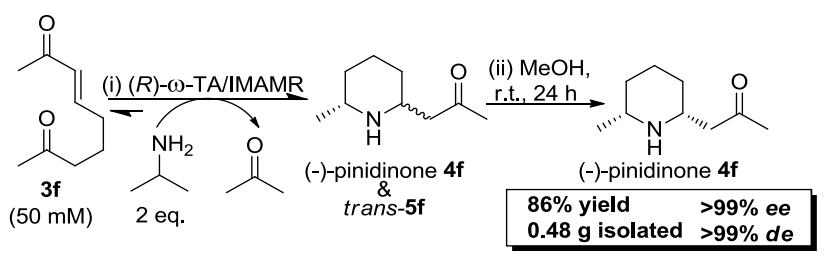

To support our hypothesis that the amine functionality can be shuttled across the molecular framework, amino ketone $\mathbf{6 f}$ was synthesized in 5 steps (see ESI) and exposed to ATA117 in the absence of any additional amine donor or acceptor (Scheme 2). After $\mathbf{2 4}$ h, complete consumption of $\mathbf{6 f}$ was observed along with the formation of a mixture of (-)-pinidinone $4 \mathbf{f}$ and trans-5f. To our knowledge, this is the first example of an $\omega$-TA reaction that does not require a separate donor and acceptor. The enzyme bound PLP forms pyridoxamine phosphate (PMP) using $6 f$ as the amine donor and generates diketone $\mathbf{z f}$. The amine functionality is then shuttled to the more thermodynamically stable ketone, which readily undergoes an IMAMR. While bis-amine $\mathbf{7 f}$ was not observed during the course of the reaction, it is likely that it is an intermediate. The efficiency of this conversion is striking, as the single amine equivalent available in the reaction has come from the starting material $\mathbf{6 f}$. 
Scheme 2. Proposed mechanism for the formation of (-)pinidinone $4 \mathrm{f}$ and trans- $5 \mathrm{f}$ from the single amine equivalent $6 f$.

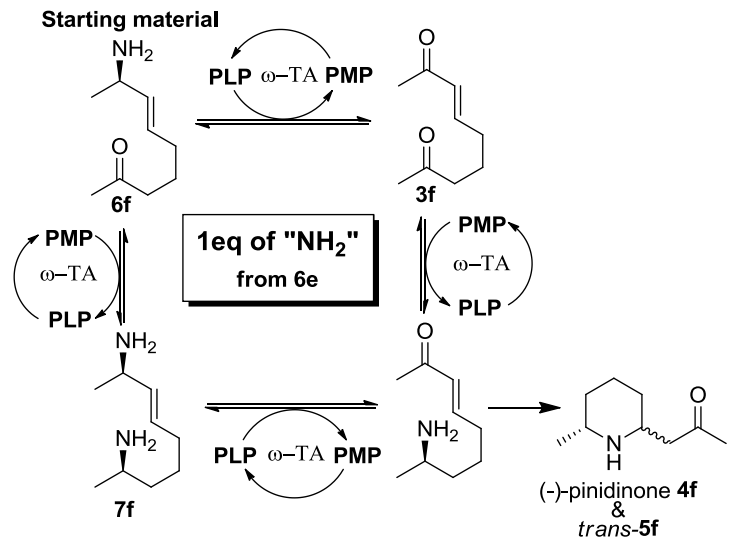

In conclusion, we have developed an extremely efficient biocatalytic aza-Michael strategy for the enantioselective conversion of pro-chiral ketoenones to 2,6-disubstituted piperidines, with excellent conversion and isolated yield. Our approach reveals that coupling a reversible $\omega$-TA reaction with a strong thermodynamic driving force allows the amine functionality to be shuttled across a molecular framework to form the desired product. This work significantly expands the scope of $\omega$ TA methodology in total synthesis and we are currently exploring the utility of this dynamic chemistry for the synthesis of more complex alkaloid scaffolds.

\section{ASSOCIATED CONTENT}

\section{Supporting Information}

The supporting information contains details of compound preparation, characterization and NMR/GC/HPLC spectra. This material is available free of charge via the Internet at http://pubs.acs.org.

\section{AUTHOR INFORMATION}

\section{Corresponding Authors}

*v.caprio@mmu.ac.uk

*elaine.oreilly@nottingham.ac.uk

*b.macia-ruiz@mmu.ac.uk

Notes

The authors declare no competing financial interests.

\section{ACKNOWLEDGMENT}

The authors acknowledge MMU for funding JR's PhD scholarship. VC and EOR thank RKE (MMU) for an incentivisation award. BM thanks the European Commission for a Marie Curie Career Integration Grant (PCIG12-GA-2012-333834 MASPGREEN) and the EPSRC for a First Grant (EP/Moooo28/1). EOR acknowledges funding from the BBSRC (BB/Mo21947/1).

\section{REFERENCES}

(1) (a) Sánchez-Roselló, M.; Acena, J.; Simón-Fuentes, A.; del Pozo, C. Chem. Soc. Rev. 2014, 43, 7430-7453. (b) Amara, Z.; Caron, J.; Joseph, D. Nat. Prod. Rep. 2013, 30, 1211-1125. (c) Enders, D.; Wang, C.; Leibich, J. X. Chem. Eur. J. 2oo9, 15, 11058-11076. (d) Krishna, P. R.;
Sreeshailam, A.; Srinivas, R. Tetrahedron 2009, 65, 9657-9672. (e) Vicario, J. L.; Badía, D.; Carrillo, L. Synthesis 2007, 2065-2092. (f) Xu, L.W.; Xia, C.-G. Eur. J. Org. Chem. 2005, 633-639.

(2) (a) Guerola, M.; Sánchez-Roselló, M.; Mulet, C.; del Pozo, C.; Fustero, S. Org. Lett. 2015, 17, 96o-963. (b) Krishna, P. A.; Reddy, B. K. Tetrahedron Asymmetry 2013, 24, 758-763. (c) Fustero, S.; Monteagudo, S.; Sánchez-Roselló, M.; Flores, S.; Barrio, P.; del Pozo, C. Chem. Eur. J. 2010, 16, 9835-9845. (d) Zhong, C.; Wang, Y.; Hung, A. W.; Schreiber, S. L.; Young, D. W. Org. Lett. 2011, 13, 5556-5559. (e) Bandini, M.; Eichholzer, A.; Tragni, M.; Umani-Ronchi, A. Angew. Chem. 2008, 120, 3282-3285. (f) Fustero, S.; Moscardó, J.; Jiménez, D.; Pérez-Carrión, M. D.; Sánchez-Roselló, M.; del Pozo, C. Chem. Eur. J. 20o8, 14, 9868-9872. (g) Carlson, E. C.; Rathbone, L. K.; Yang, H.; Collett, N. D.; Carter, R. G. J. Org. Chem. 2oo8, 73, 5155-5158. (h) Fustero, S.; Jiménez, D.; Moscardó, J.; Catalán, S.; del Pozo, C. Org. Lett. 2007, 9, 5283-5286. (i) Rejzek, M.; Stockman, R. A.; Hughes, D. L. Org. Biomol. Chem. 2005, 3, 73-83. (j) Takasu, K.; Maiti, S.; Ihara, M. Heterocycles 2003, 59, 51-55. (k) Felpin, X-F, Lebreton, J. J. Org. Chem. 2002, 67, 9192-9199. (l) Rejzek, M.; Stockman, R. A. Tetrahedron Lett. 2002, 43, 6505-6506. (m) Banwell, M, G.; Bui, C. T.; Pham, H. T. T.; Simpson, G. W. J. Chem. Soc., Perkin Trans. 1 1996, 967-969.

(3) (a) O'Reilly, E.; Turner, N. J. Nat. Chem. Biol. 2013, 9, 285-288. (b) Organic Synthesis Using Biocatalysis; Stewart, J. and Goswami, A., Ed; Elsevier: Amsterdam, The Netherlands, 2016.

(4) (a) Savile, C. K.; Janey, J. M.; Mundorff, E. C.; Moore, J. C.; Tam, S.; Jarvis, W. R.; Colbeck, J. C.; Krebber, A.; Fleitz, F. J.; Brands, J.; Devine, P. N.; Huisman, G. W.; Hughes, G. J. Science 2010, 329, 305-309. (b) Fuchs, M.; Farnberger, J.; Kroutil, W. Eur. J. Org. Chem. 2015, 6965-6982. (c) Ghislieri, D.; Turner, N. J. Top. Catal. 2014, 57, 284-30o. (d) Nestl, B. M.; Hammer, S. C.; Nebel, B. A.; Hauer, B. Angew. Chem. Int. Ed. 2014, 53, 3070-3095. (e) Cuetos, A.; García-Ramos, M.; Fischereder, E.-M.; Díaz-Rodríguez, A.; Grogan, G.; Gotor, V.; Kroutil, W.; Lavandera, I. Angew. Chem. Int. Ed. 2016, 55, 3144-3147. (f) O'Reilly, E.; Turner, N. J. Perspectives in Science 2015, 4, 55-61. (g) O’Reilly, E.; Iglesias, C.; Turner, N. J. ChemCatChem 2014, 6, 992-995. (h) Mathew, S.; Yun, H. ACS Catal. 2012, 2, 993-1001.

(5) Koszelewski, D.; Tauber, K.; Faber, K.; Kroutil, W. Trends Biotechnol. 2010, 28, 324-332. (b) Cassimjee, K. E.; Humble, M. S.; Miceli, V.; Colomina, C.; Berglund, G. P. ACS Catal. 2011, 1, 1051-1055.

(6) (a) O'Reilly, E.; Iglesias, C.; Ghislieri, D.; Hopwood, J.; Galman, J. L.; Lloyd, R. C.; Turner, N. J. Angew. Chem. 2014, 53, 2447-2450. (b) Simon, R. C.; Grischek, B.; Zepeck, F, Steinreiber, A.; Belaj, F.; Kroutil, W. Angew. Chem. Int. Ed. 2012, 51, 6713-6716.

(7) The synthesis of 2,6-disubstiuted piperidines is of great interest, owing to their wide occurrence as natural and non-natural bioactive therapeutics and agrochemicals. See, for example: (a) Struntz, G. M.; Findlay, J. A. In The Alkaloids; Brossi, A., Ed.; Academic: New York, 1985; Vol. 26, pp 89-193. (b) Schneider, M. In Alkaloids: Chemical and Biological Perspectives; Pelletier, S.W., Ed.; Pergamon: Oxford, 1996; Vol. 10, pp 155-299. (c) Chalard, P.; Remuson, R.; Gelas-Mialhe, Y.; Gramain, J.-C. Tetrahedron-Asymmetr 1998, 9, 4361-4368. (d) Bates, R. W.; Sa-Ei, K. Tetrahedron 20o2, 58, 5957-5978. (e) Weintraub, P. M.; Sabol, J. S.; Kane, J. M.; Borcherding, D. R. Tetrahedron 2003, 59, 2953-2989. (f) Couty, F.; Evano, G.; Darro, F.; Kiss, R. Eur. J. Org. Chem. 2003, 2062-2070. (g) Felpin, F.-X.; Lebreton, J. Tetrahedron 2004, 6o, 10127-10153.

(8) $(R, R)$-4e was prepared using $(R)$-selective ATAo25 in $2 \%$ yield (see SI for further details) for ee determination purposes. No optimization on the TA enzyme selection with substrate $\mathbf{3} \mathbf{e}$ has been carried out.

(9) Csatayova, K.; Spanik, I.; Durisova, V.; Szolcsanyi, P. Tetrahedron Lett. 2010, 51, 6611-6614.

(10) For previous synthesis of (-)-pinidinone: (a) Shankaraiah, G.; Kumar T. V.; Reddy, G. V.; Rao, J. M.; Babu, K. S. Helv. Chem. Acta 2013, 96, 990-996. (b) Kumaraswamy, G.; Jayaprakash, N.; Balakishan, G. Org. Biomol. Chem. 2011, 9, 7913-7920. (c) Kavala, M.; Mathia, F.; Kozisek, J.; Szolcsanyi, P. J. Nat. Prod. 2011, 74, 803-808. (d) Freville, 
S.; Delbecq, P.; Thuy, V. M.; Petit, H.; Celerier, J. P.; Lhommet, G. Tetrahedron Lett. 2001, 42, 4609-4611. (e) Munchhoff, M.; Meyers, A. I. J. Am. Chem. Soc. 1995, 117, 5399-5540.

\section{TOC Graphic}

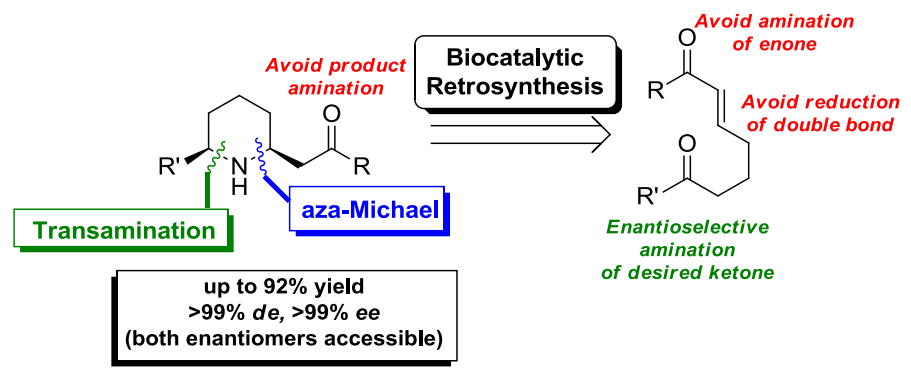

